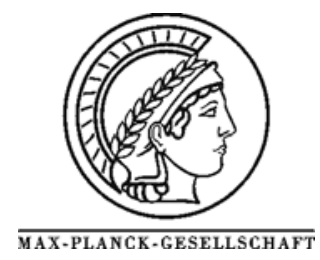

\title{
The influence of water on the dispersion of vanadia supported on silica SBA-15
}

\author{
C. Hess*, R. Schlögl \\ Department of Inorganic Chemistry, Fritz-Haber-Institute of the MPG, Faradayweg 4-6, 14195 Berlin, Germany \\ *Corresponding author: e-mail hess@ffhi-berlin.mpg.de,
}

Received 11 October 2006; in final form 17 October 2006, available online 21 October 2006

\begin{abstract}
The influence of water on the dispersion of silica SBA-15 supported vanadia model catalysts has been studied using X-ray photoelectron spectroscopy (XPS) as well as UV-VIS and Raman spectroscopy. XPS characterization of the V2 $\mathrm{p}_{3 / 2}$ state reveals the presence of two $\mathrm{V}^{5+}$ states, which are assigned to vanadia with distinctly different cluster size. Upon dehydration a dramatic change in their intensity ratio is observed as a result of a substantial increase in the vanadia dispersion. It is shown that the observed changes in vanadia dispersion are directly associated with the changes in the molecular structure of the surface vanadia species.
\end{abstract}

Keywords: supported vanadium oxide, vanadia, SBA-15, XPS, dispersion

\section{Introduction}

Supported vanadium oxide catalysts exhibit a large potential for a variety of oxidation reactions such as the selective oxidation of methane and methanol to formaldehyde and the oxidative dehydrogenation of ethane and propane [1]. However, despite extensive research there are still fundamental aspects of supported metal oxide catalysts, which have not been addressed in the literature adequately to their importance, such as changes in catalyst dispersion during reaction [2]. Water is a common product of selective oxidation reactions of alkanes. Also, water vapour is often added to the feed to improve the catalyst performance. The conditions of operation allow for hydrothermal reactions involving oxolation and olation processes leading to polymerization/depolymerization of an initial $\mathrm{V}_{\mathrm{x}} \mathrm{O}_{\mathrm{y}}$ condensate. It is known from the literature that the structure of the fully hydrated state of silica-supported vanadia species closely resembles $\mathrm{V}_{2} \mathrm{O}_{5} \cdot n \mathrm{H}_{2} \mathrm{O}$ gels with vanadium in pseudo-octahedral coordination forming layers of twodimensional polyvanadates [3-5]. Dehydrated vanadia at low $\mathrm{V}$ coverages, i.e. below the coverage at which $\mathrm{V}_{2} \mathrm{O}_{5}$ is formed, is proposed to be present as isolated tetrahedral $\mathrm{VO}_{4}[4,5]$ and as a mixture of isolated and small aggregates of tetrahedral $\mathrm{VO}_{4}[3,6]$. However, this assignment is currently under debate $[7,8]$.
The dispersion of supported metal oxides catalysts can be determined by measuring the oxygen uptake of the reduced active phase (e.g. vanadium oxide) in an oxygen chemisorption experiment [9]. This indirect method allows for evaluation of the fraction of accessible active phase atoms, but results may be complicated by the uncertainty of the extent of reduction of the active phase. In contrast, XPS can provide direct information on the dispersion of supported metal oxide catalysts [10] such as vanadia supported on $\mathrm{SiO}_{2}, \mathrm{Al}_{2} \mathrm{O}_{3}$ [11] and $\mathrm{TiO}_{2}$ [12]. Interestingly, in previous XPS studies on silica supported vanadia catalysts and vanadia-silica mixed oxide systems $\mathrm{V}$ species with $\mathrm{V} 2 \mathrm{p}_{3 / 2}$ binding energies of up to $2 \mathrm{eV}$ higher compared to those of reference compounds such as $\mathrm{V}_{2} \mathrm{O}_{5}$ were found, which were attributed to vanadium species strongly interacting with silica [13-17]. However, the above studies were performed on samples exposed to air before being introduced into the XPS chamber without further treatment. Despite the well-known influence of water on the structure of supported vanadia, XPS has not yet been applied to study the effect of dehydration on the vanadia dispersion.

For a detailed understanding of catalyst properties, the use of materials with well-defined structure is necessary. Therefore, we have prepared vanadium oxide model catalysts via controlled grafting/anion exchange, which consist of highly dispersed vanadium oxide supported on the inner pores of the well-ordered mesoporous matrix of 
silica SBA-15 [18-20]. Only recently, we have demonstrated the excellent catalytic properties of this catalyst system in the propane partial oxidation to acrylic acid as well as methanol partial oxidation to formaldehyde [21,22].

In this contribution, we present a combined UV-VISRaman- XPS analysis of the changes associated with the transformation of the hydrated catalyst precursor into its highly dispersed dehydrated state. We observed changes in the photoelectron spectrum of a supported vanadium oxide powder catalyst upon calcination, which can be directly related to changes in catalyst dispersion. The focus of our study is highly dispersed vanadia supported by silica SBA15 with vanadium loadings up to $5.4 \mathrm{wt} \% \mathrm{~V}$, which is well below the loading at which $\mathrm{V}_{2} \mathrm{O}_{5}$ is formed.

\section{Experimental}

\subsection{Catalyst Preparation}

Details of the catalyst preparation are described elsewhere [18]. Briefly, functionalization of SBA-15 was achieved by adding 3-aminopropyltrimethoxysilane (APTMS) to a suspension of SBA-15 in toluene at $65^{\circ} \mathrm{C}$. After stirring for 12 hours, the contents were filtered, washed and finally stirred in $0.3 \mathrm{M} \mathrm{HCl}$ for 12 hours. For SBA-15 supported vanadium oxide catalysts (V/SBA-15), appropriate amounts of butylammonium decavanadate were added to a suspension of functionalized SBA-15 in water. The resulting yellowish powder was calcined at $550^{\circ} \mathrm{C}$ for 12 hours.

Two reference samples with approximately the same vanadium concentration $\left(0.7 \mathrm{~V} / \mathrm{nm}^{2}\right)$ as $2.7 \mathrm{wt} \% \mathrm{~V} / \mathrm{SBA}-15$ (see Table 1) were prepared. The first sample, denoted as V/SBA-15 (im), is a SBA-15 supported vanadium oxide sample prepared in a glovebox by incipient wetness impregnation using a 2-propanol solution of vanadium isopropoxide ( $\mathrm{VO}\left(\mathrm{O}-\mathrm{Pr}_{\mathrm{i}}\right)_{3}$, Alfa Aesar, 95-99\% purity). The sample was dried in $\mathrm{He}$ flow at $120^{\circ} \mathrm{C}$ for $1 \mathrm{~h}$ and at $300^{\circ} \mathrm{C}$ for $2 \mathrm{~h}$. Then the sample was calcined in air at $550^{\circ} \mathrm{C}$ for $2 \mathrm{~h}$. The second sample, denoted as $\mathrm{V} / \mathrm{SiO}_{2} / \mathrm{Si}$ (im), was prepared on a flat $\mathrm{Si}(100)$ wafer via spin-coating impregnation adopting the procedure developed by Thüne et al. [23] for the preparation of silica supported chromia to vanadia. Spin-coating was performed in air at $2800 \mathrm{rpm}$ using a 2propanol solution of vanadium isopropoxide. After impregnation the sample was calcined in air at $550^{\circ} \mathrm{C}$ for $2 \mathrm{~h}$. The $\mathrm{V}$ loading was determined based on the model by Hardeveld et al. [24].

\subsection{Physical Characterization}

The vanadium content of the catalyst samples was determined by ICP-AES (inductively coupled plasma atomic emission spectroscopy). Surface areas of the prepared samples were measured by nitrogen adsorption/desorption isotherms and standard multipoint BET analysis methods. The pore volume was determined from the adsorption branch of the $\mathrm{N}_{2}$ isotherm curve at the $\mathrm{P} / \mathrm{P}_{0}=0.95$ signal point. The pore-size distribution was calculated from the isotherm using the NLDFT method.

\subsection{Raman Spectroscopy}

For the Raman experiments the powder samples were introduced into a stainless steel sample holder with a $0.6 \mathrm{~mm}$ deep rectangular well covering an area of $(12 \times 8) \mathrm{mm}^{2}$. Raman spectra were measured using $514 \mathrm{~nm}$ excitation $(5 \mathrm{~mW})$ at $5 \mathrm{~cm}^{-1}$ spectral resolution (Kaiser Optical). Raman spectra under dehydrated conditions were recorded at room temperature after treating the samples in flowing air at $300^{\circ} \mathrm{C}$ for $30 \mathrm{~min}$. Sampling times were typically $30 \mathrm{~min}$.

\subsection{UV-VIS Diffuse Reflectance Spectroscopy}

Diffuse reflectance UV-VIS spectra were measured with a Perkin Elmer Lamba 950 UV-VIS spectrometer equipped with a Harrick diffuse reflectance attachment. Samples were first measured as is (hydrated state) at room temperature. Then they were dehydrated in $50 \% \mathrm{O}_{2} / 50 \% \mathrm{~N}_{2}$ at $300^{\circ} \mathrm{C}$ for $1 / 2 \mathrm{~h}$ before measuring spectra at $40^{\circ} \mathrm{C}$. The Kubelka-Munk function $\left(\mathrm{F}\left(\mathrm{R}_{\infty}\right)\right)$ was used to convert diffuse reflectance data into absorption spectra using $\mathrm{BaSO}_{4}$ as a standard.

\subsection{X-ray photoelectron spectroscopy}

The measurements were carried out using a modified LHS/SPECS EA200 MCD system equipped with a $\mathrm{Mg} \mathrm{\textrm {K } _ { \alpha }}$ source $(1253.6 \mathrm{eV}, 168 \mathrm{~W})$. The binding energy scale of the system was calibrated using $\mathrm{Au} 4 \mathrm{f}_{7 / 2}=84.0 \mathrm{eV}$ and $\mathrm{Cu} 2 \mathrm{p}_{3 / 2}=932.67 \mathrm{eV}$ from foil samples. The powder samples were placed as is in a stainless steel sample holder with a $0.6 \mathrm{~mm}$ deep rectangular well covering an area of $(12 \times 8) \mathrm{mm}^{2}$. The base pressure of the ultra-high vacuum (UHV) chamber was $1 \times 10^{-10}$ mbar. During the XPS experiments the pressure increased to about $1 \times 10^{-9}$ mbar. Data acquisition time was $100 \mathrm{~min}$. To account for the effect of UHV/X-ray induced changes on the XP spectra series of spectra as a function of time were recorded. The temporal changes of the binding energies of the V 2p3/2 components can be well described by a first order exponential decay and were used to determine their values at $t=0$. Charging of the powder samples was accounted for by setting the peak of the Si $2 p$ signal to $103.6 \mathrm{eV}$ [19]. For the hydrated (air-exposed) sample the $\mathrm{C} 1 \mathrm{~s}$ signal from adventitious carbon was located at $284.7 \mathrm{eV}$ in excellent agreement with the common reference value of $284.7 \pm 0.5 \mathrm{eV}$ [25]. Further data reduction included satellite deconvolution and subtraction of a Shirley background. Quantitative data analysis was performed on the basis of peak areas by 
Table 1: BET characteristics of the synthesized SBA-15 supported vanadium oxides compared to the blank SBA-15 support.

\begin{tabular}{lcccccc}
\hline & $\begin{array}{c}\mathrm{V} \\
(\mathrm{wt} \%)\end{array}$ & $\mathrm{V} / \mathrm{nm}^{2}$ & $\begin{array}{c}\mathrm{V} \\
(\mathrm{mmol} / \mathrm{g})\end{array}$ & $\begin{array}{c}\mathrm{S}_{\mathrm{BET}} \\
\left(\mathrm{m}^{2} / \mathrm{g}\right)\end{array}$ & $\begin{array}{c}\mathrm{d}_{\mathrm{p}} \\
(\mathrm{nm})\end{array}$ & $\begin{array}{c}\mathrm{V}_{\mathrm{p}} \\
(\mathrm{mL} / \mathrm{g})\end{array}$ \\
\hline SBA-15 & 0.0 & 0.0 & 0.0 & 897 & 7.0 & 1.1 \\
$4.4 \mathrm{wt} \%$ V/SBA-15 (im) & 3.6 & 0.7 & 0.71 & 646 & 6.8 & 0.8 \\
$2.7 \mathrm{wt} \%$ V/SBA-15 & 2.7 & 0.7 & 0.53 & 445 & 6.7 & 0.5 \\
$5.4 \mathrm{wt} \%$ V/SBA-15 & 5.4 & 1.4 & 1.05 & 440 & 6.6 & 0.5 \\
\hline
\end{tabular}

fitting with 30/70 Gauss-Lorentz product functions. Atomic ratios were calculated using empirical cross sections [26]. Spectra under dehydrated conditions were recorded at room temperature after sample treatment in $200 \mathrm{mbar} \mathrm{O}_{2}$ at $300^{\circ} \mathrm{C}$ for $5 \mathrm{~min}$ and subsequent transfer to the analysis chamber without exposure to air (quasi in situ).

\subsection{X-ray photoelectron spectroscopy}

The measurements were carried out using a modified LHS/SPECS EA200 MCD system equipped with a $\mathrm{Mg} \mathrm{K} \mathrm{K}_{\alpha}$ source $(1253.6 \mathrm{eV}, 168 \mathrm{~W})$. The binding energy scale of the system was calibrated using $\mathrm{Au} 4 \mathrm{f}_{7 / 2}=84.0 \mathrm{eV}$ and $\mathrm{Cu} 2 \mathrm{p}_{3 / 2}=932.67 \mathrm{eV}$ from foil samples. The powder samples were placed as is in a stainless steel sample holder with a $0.6 \mathrm{~mm}$ deep rectangular well covering an area of $(12 \times 8) \mathrm{mm}^{2}$. The base pressure of the ultra-high vacuum (UHV) chamber was $1 \times 10^{-10}$ mbar. During the XPS experiments the pressure increased to about $1 \times 10^{-9}$ mbar. Data acquisition time was $100 \mathrm{~min}$. To account for the effect of UHV/X-ray induced changes on the XP spectra series of spectra as a function of time were recorded. The temporal changes of the binding energies of the V $2 \mathrm{p} 3 / 2$ components can be well described by a first order exponential decay and were used to determine their values at $t=0$. Charging of the powder samples was accounted for by setting the peak of the Si $2 p$ signal to $103.6 \mathrm{eV}$ [19]. For the hydrated (air-exposed) sample the $\mathrm{C} 1 \mathrm{~s}$ signal from adventitious carbon was located at $284.7 \mathrm{eV}$ in excellent agreement with the common reference value of $284.7 \pm 0.5 \mathrm{eV}$ [25]. Further data reduction included satellite deconvolution and subtraction of a Shirley background. Quantitative data analysis was performed on the basis of peak areas by fitting with 30/70 Gauss-Lorentz product functions. Atomic ratios were calculated using empirical cross sections [26]. Spectra under dehydrated conditions were recorded at room temperature after sample treatment in $200 \mathrm{mbar}_{2} \mathrm{O}_{2}$ at $300^{\circ} \mathrm{C}$ for $5 \mathrm{~min}$ and subsequent transfer to the analysis chamber without exposure to air (quasi in situ).

\section{Results and Discussion}

The results of the $\mathrm{N}_{2}$ physisorption analysis of SBA15 and the SBA-15 supported vanadium oxide samples are given in Table 1. With the deposition of vanadium oxide, the surface area, pore radius and pore volume shift to lower values, which suggests that the vanadia species are located inside the pores of SBA-15, coating the inner walls of the mesoporous matrix [18]. However, physisorption data also reveal that in the presence of surface vanadia, the mesoporous channels remain accessible for reactants. The lower surface area of $2.7 \mathrm{wt} \%$ V/SBA-15 compared to $4.4 \mathrm{wt} \% \mathrm{~V} / \mathrm{SBA}-15$ (im) (see Table 1) is a result of the organofunctionalization of SBA-15 in the course of the multi-step preparation procedure [18,19].

Figure 1 depicts a detailed XP spectrum of the V2 $\mathrm{p}_{3 / 2}$ region of $2.7 \mathrm{wt} \% \mathrm{~V} / \mathrm{SBA}-15$ (spectrum $\mathrm{b}$ ) together with the corresponding spectrum of blank SBA-15 (spectrum a) after satellite subtration. As the spectrum of SBA-15 shows structure in the $\mathrm{V} 2 \mathrm{p}$ region, it was used for background subtraction. The resulting spectrum is shown on the top of Figure 1 (spectrum c). The same procedure was applied to all other XP raw spectra.

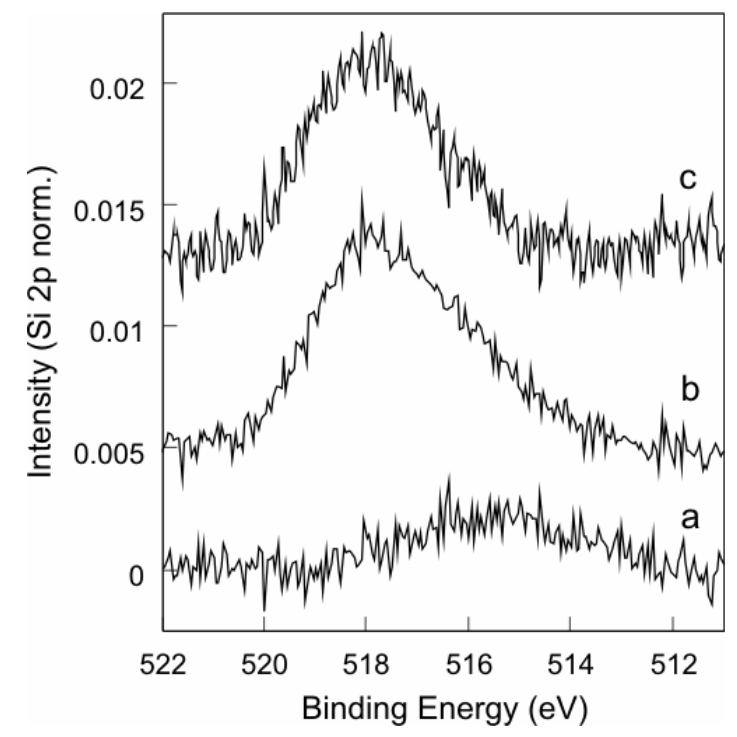

Figure 1: XP spectra of (a) blank SBA-15 and (b) $2.7 \mathrm{wt} \% \mathrm{~V} / \mathrm{SBA}-15$. The resulting background-subtracted spectrum of $2.7 \mathrm{wt} \% \mathrm{~V} / \mathrm{SBA}-15$ is shown in (c). The spectra are offset for clarity. 
Table 2: Results of the $\mathrm{V} 2 \mathrm{p}_{3 / 2}$ analysis of $\mathrm{SBA}-15$ and $\mathrm{SiO}_{2} / \mathrm{Si}$ supported vanadium oxides.

\begin{tabular}{lccr}
\hline & $\begin{array}{c}\text { position } \\
(\mathrm{eV})\end{array}$ & $\begin{array}{c}\text { width } \\
(\mathrm{eV})\end{array}$ & $\%$ \\
\hline $\mathrm{V} / \mathrm{SiO}_{2} / \mathrm{Si}(\mathrm{im})$ & 518.7 & 2.0 & 48.4 \\
(hydrated) & 517.4 & 2.0 & 46.4 \\
& 515.9 & 2.0 & 5.2 \\
\hline $4.4 \mathrm{wt} \% \mathrm{~V} / \mathrm{SBA}-15(\mathrm{im})$ & 518.7 & 2.0 & 42.4 \\
(hydrated) & 517.4 & 2.0 & 47.6 \\
& 515.9 & 2.0 & 10.0 \\
\hline $2.7 \mathrm{wt} \% \mathrm{~V} / \mathrm{SBA}-15$ & 518.7 & 2.0 & 45.0 \\
(hydrated) & 517.4 & 2.0 & 46.6 \\
& 515.9 & 2.0 & 8.4 \\
\hline
\end{tabular}

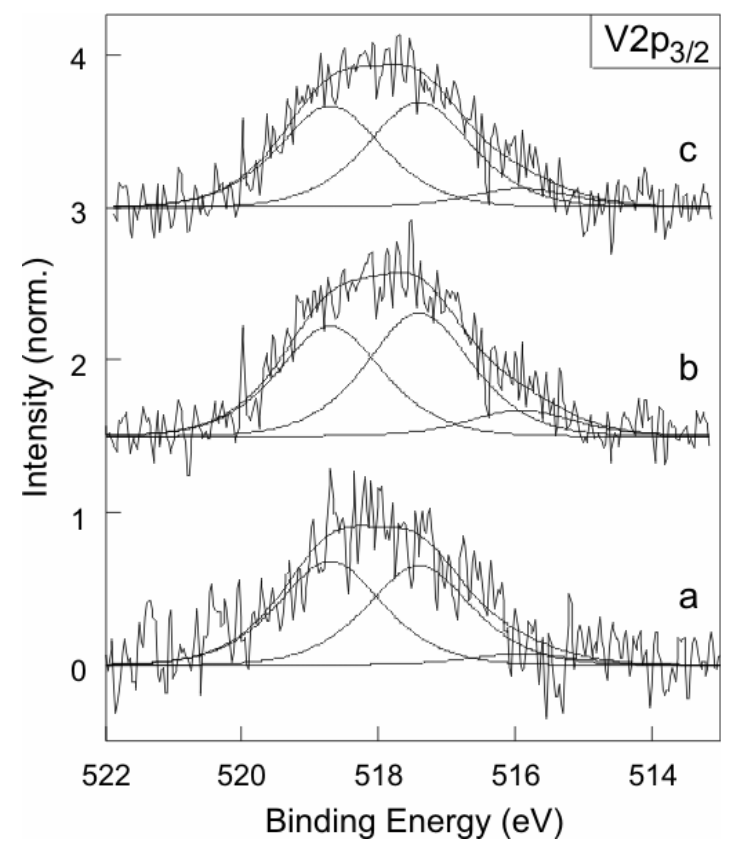

Figure 2: $\mathrm{XP} \mathrm{V} 2 \mathrm{p}_{3 / 2}$ spectra of (a) $\mathrm{V} / \mathrm{SiO}_{2} / \mathrm{Si}$ (im), (b) $2.7 \mathrm{wt} \% \mathrm{~V} / \mathrm{SBA}-15$ (im) and (c) $2.7 \mathrm{wt} \% \mathrm{~V} / \mathrm{SBA}-15$. The spectra are offset for clarity.

The influence of charging and sample preparation on the XP spectra was studied using two reference samples with the same vanadium concentration $\left(0.7 \mathrm{~V} / \mathrm{nm}^{2}\right)$ as $2.7 \mathrm{wt} \% \mathrm{~V} / \mathrm{SBA}-15$. Figure 2 shows the normalized XP spectra of the $\mathrm{V} 2 \mathrm{p}_{3 / 2}$ region of $\mathrm{V} / \mathrm{SiO}_{2} / \mathrm{Si}$ (im) (spectrum a), $4.4 \mathrm{wt} \% \mathrm{~V} / \mathrm{SBA}-15 \mathrm{(im)}$ (spectrum b) and $2.7 \mathrm{wt} \%$ V/SBA-15 (spectrum c) together with the least-square fits to the data. As will be discussed below, for quantitative analysis the data was deconvoluted into three peaks with binding energies at 518.7, 515.4 and $515.9 \mathrm{eV}$, respectively, and a constant FWHM $(2.0 \mathrm{eV})$. The results of the peak-fitting analysis are summarized in Table 2. The $\mathrm{V} / \mathrm{SiO}_{2} / \mathrm{Si}(\mathrm{im})$ sample represents a surface science model of silica supported vanadium oxide for which charging is largely removed [27]. The $\mathrm{V} 2 \mathrm{p}_{3 / 2}$ signal of $\mathrm{V} / \mathrm{SiO}_{2} / \mathrm{Si}$ (im) strongly resembles that of the $2.7 \mathrm{wt} \% \mathrm{~V} / \mathrm{SBA}-15$ powder catalyst regarding position, width and intensity distribution. Thus it is reasonable to conclude that charging does not have a significant effect on the $V 2 p_{3 / 2}$ emission of the V/SBA-15 powders samples studied. Also, comparison of the $\mathrm{V} 2 \mathrm{p}_{3 / 2}$ signal of $2.7 \mathrm{wt} \% \mathrm{~V} / \mathrm{SBA}-15$ with that of $4.4 \mathrm{wt} \% \mathrm{~V} / \mathrm{SBA}-15$ (im), which was prepared by impregnation of a 2-propanol solution of vanadium isopropoxide onto SBA-15 confirms that the preparation procedure has no noticeable influence on the position and shape of the $\mathrm{V} 2 \mathrm{p}_{3 / 2}$ spectrum.

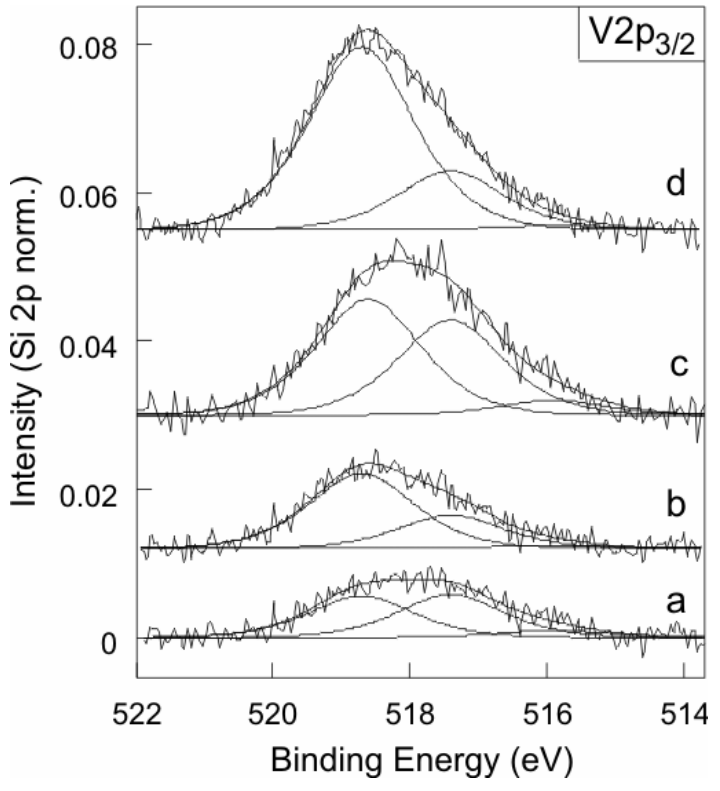

Figure 3: $\mathrm{XP} \quad \mathrm{V} 2 \mathrm{p}_{3 / 2}$ spectra of (a) hydrated $2.7 \mathrm{wt} \% \mathrm{~V} / \mathrm{SBA}-15$, (b) dehydrated $2.7 \mathrm{wt} \% \mathrm{~V} / \mathrm{SBA}-15$, (c) hydrated $5.4 \mathrm{wt} \% \mathrm{~V} / \mathrm{SBA}-15$ and (d) dehydrated $5.4 \mathrm{wt} \%$ V/SBA-15. The spectra are offset for clarity.

Figure 3 shows the $\mathrm{V} 2 \mathrm{p}_{3 / 2}$ emission of $2.7 \mathrm{wt} \% \mathrm{~V} / \mathrm{SBA}-15$ and $5.4 \mathrm{wt} \% \mathrm{~V} / \mathrm{SBA}-15$ in their hydrated (spectra a and c) and dehydrated (spectra b and d) state together with least-square fit to the data. As no noticeable change of the XP spectra and Raman spectra (see below) was observed over several months, we conclude that the hydrated spectra shown correspond to the fully equilibrated state of silica supported vanadia in air at room temperature. Upon dehydration a significant increase in total intensity and a substantial redistribution of spectral weight to higher binding energies (BE) are observed. Quantitative 
Table 3: Results of the V2 $\mathrm{p}_{3 / 2}$ analysis of SBA-15 supported vanadium oxides.

\begin{tabular}{|c|c|c|c|c|c|}
\hline & $\begin{array}{c}\text { position } \\
(\mathrm{eV})\end{array}$ & $\begin{array}{l}\text { width } \\
(\mathrm{eV})\end{array}$ & $\begin{array}{c}\% \\
(\mathrm{t}=100 \mathrm{~min})\end{array}$ & $\begin{array}{c}\% \\
(\mathrm{t}=0 \mathrm{~min})\end{array}$ & $\mathrm{V} / \mathrm{Si}$ \\
\hline $2.7 \mathrm{wt} \% \mathrm{~V} / \mathrm{SBA}-15$ & 518.7 & 2.0 & 45.0 & 46.0 & 0.024 \\
\hline (hydrated) & $\begin{array}{l}517.4 \\
515.9\end{array}$ & $\begin{array}{l}2.0 \\
2.0\end{array}$ & $\begin{array}{r}46.6 \\
8.4\end{array}$ & 54.0 & \\
\hline $2.7 \mathrm{wt} \% \mathrm{~V} / \mathrm{SBA}-15$ & 518.7 & 2.0 & 66.6 & 65.0 & \\
\hline $\begin{array}{l}\text { after } \mathrm{O}_{2} \text { treatment } \\
\text { (dehydrated) }\end{array}$ & $\begin{array}{l}517.4 \\
515.9\end{array}$ & $\begin{array}{l}2.0 \\
2.0\end{array}$ & $\begin{array}{r}30.1 \\
3.3\end{array}$ & 35.0 & 0.029 \\
\hline $5.4 \mathrm{wt} \% \mathrm{~V} / \mathrm{SBA}-15$ & 518.7 & 2.0 & $\begin{array}{r}5.3 \\
51.3\end{array}$ & 51.1 & 0.052 \\
\hline (hydrated) & $\begin{array}{l}517.4 \\
515.9\end{array}$ & $\begin{array}{l}2.0 \\
2.0\end{array}$ & $\begin{array}{r}42.2 \\
6.5\end{array}$ & 48.9 & \\
\hline $\begin{array}{l}5.4 \mathrm{wt} \% \mathrm{~V} / \mathrm{SBA}-15 \\
\text { after } \mathrm{O}_{2} \text { treatment } \\
\text { (dehydrated) }\end{array}$ & $\begin{array}{l}518.6 \\
517.4 \\
515.9\end{array}$ & $\begin{array}{l}2.0 \\
2.0 \\
2.0\end{array}$ & $\begin{array}{r}74.5 \\
23.9 \\
1.6\end{array}$ & $\begin{array}{l}72.0 \\
28.0\end{array}$ & 0.061 \\
\hline
\end{tabular}

analysis was performed using three fit functions with constant FWHM $(2.0 \mathrm{eV})$. The results from the peak-fitting analysis are summarized in Table 3. By recording timedependent XP spectra we were able to account for the effect of UHV/X-ray induced changes and determine the corresponding $\mathrm{BE}$ values at $\mathrm{t}=0 \mathrm{~min}$ (see experimental). The analysis yields an intensity increase of the band around $518.7 \mathrm{eV}$ from $46 \%(51 \%)$ to $65 \% \quad(72 \%)$ for $2.7 \mathrm{wt} \% \mathrm{~V} / \mathrm{SBA}-15 \quad(5.4 \mathrm{wt} \% \mathrm{~V} / \mathrm{SBA}-15)$. Likewise the band centered at $517.4 \mathrm{eV}$ shows an intensity decrease from $54 \%$ (49\%) to $35 \%$ (28\%).

Comparison with literature data on $\mathrm{V} 2 \mathrm{p}_{3 / 2}$ BE for binary and supported vanadia allows assigning the bands at $515.9 \mathrm{eV}, 517.4 \mathrm{eV}$ and $518.7 \mathrm{eV}$ [28,29]. In general, an increase in BE with increasing oxidation state is observed. For supported and binary vanadium oxides typical BE values of 515.5-515.9 eV, 516.0-516.5 eV and 516.8-517.7 eV were reported for $\mathrm{V}^{3+}, \mathrm{V}^{4+}$ and $\mathrm{V}^{5+}$, respectively [13$17,28,29]$. By comparison with the above values the bands at $517.4 \mathrm{eV}$ and $515.9 \mathrm{eV}$ can readily be assigned to $\mathrm{V}^{5+}$ and $\mathrm{V}^{3+}$, respectively. The latter assignment is fully consistent with the results of the time-dependent analysis, which have shown an increase in intensity around $515.9 \mathrm{eV}$ with time due to UHV/X-ray induced reduction of the vanadia samples. The assignment of the band at $515.9 \mathrm{eV}$ was confirmed by electron paramagnetic resonance (EPR), which can characterize vanadium in the oxidation state +4 only. The EPR experiments on the dehydrated $2.7 \mathrm{wt} \% \mathrm{~V} / \mathrm{SBA}-$ 15 sample showed no $\mathrm{V}^{4+}$ signal and those on hydrated 2.7 $\mathrm{wt} \% \mathrm{~V} / \mathrm{SBA}-15$ gave a $\mathrm{V}^{4+}$ signal corresponding to only $0.3 \%$ of the total amount of $\mathrm{V}$. Therefore, the quantitative analysis was restricted to $\mathrm{V}^{5+}$ and $\mathrm{V}^{3+}$ species.

It is evident that the band around $518.7 \mathrm{eV}$ can not solely be described by a change in oxidation state. However, final state effects are known to result in sizedependent $\mathrm{BE}$ shifts for small conducting particles on insulating substrates [30]. This is a result of the Coulomb interaction between the photoelectron and the positively charged particle. As our sample contains $\mathrm{V}^{3+}$, and many reduced vanadium oxides such as $\mathrm{V}_{2} \mathrm{O}_{3}$ are metallic at room temperature, the above considerations are applicable to our system as well. Therefore, our XPS results directly show that dehydration of the catalyst is accompanied by a strong decrease in cluster size, i.e., an increase in the dispersion of the catalyst. The fact that the band at $518.7 \mathrm{eV}$ is present for the hydrated sample indicates that water from ambient significantly reduces the dispersion of part but not all of the surface vanadium oxide species. Likewise the results of the above analysis suggest that upon dehydration under the conditions described above not all surface vanadia is subject to the same changes in cluster size.
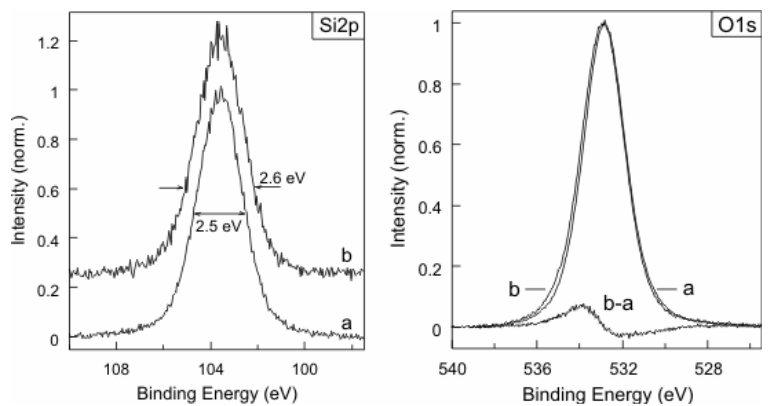

Figure 4: Left panel: XP Si2p spectra of (a) hydrated (b) dehydrated $2.7 \mathrm{wt} \% \mathrm{~V} / \mathrm{SBA}-15$. Spectra are offset for clarity. Right panel: XP O1s spectra of (a) hydrated and (b) dehydrated $2.7 \mathrm{wt} \% \mathrm{~V} / \mathrm{SBA}-15$ as well as the difference spectrum (b-a).

Figure 4 shows the normalized Si $2 \mathrm{p}$ (left) and O 1s (right) emission of $2.7 \mathrm{wt} \% \mathrm{~V} / \mathrm{SBA}-15$ in their hydrated (spectra a) and dehydrated (spectra b) state. For the $5.4 \mathrm{wt} \% \mathrm{~V} / \mathrm{SBA}-15$ sample similar results were obtained. Small changes in the peak width and position, but no changes in the peak shape were observed. Quantitative analysis shows that the $\mathrm{Si} 2 \mathrm{p}$ spectrum of the dehydrated sample (FWHM: $2.6 \mathrm{eV}$ ) exhibit a slightly larger width than the hydrated sample (FWHM: $2.5 \mathrm{eV}$ ), respectively. The $\mathrm{O} 1 \mathrm{~s}$ spectrum of the dehydrated sample is slightly shifted to higher BE values. Similar changes in the Si $2 p$ and $\mathrm{O} 1 \mathrm{~s}$ spectra have been explained by different contributions to differential charging [31]. However, as demon- 
strated above (see Fig. 2) such differences do not have a noticeable influence on the shape of the $\mathrm{V} 2 \mathrm{p}_{3 / 2}$ spectra.

The dispersion of the surface metal oxide species was studied by measuring the XPS vanadium to the support cation intensity ratio. The $\mathrm{V} / \mathrm{Si}$ intensity ratio was evaluated by using empirically derived atomic sensitivity factors (see Table 3) [26]. Theoretical studies have shown that the XPS active phase to support cation ratio can be used to predict the volume ratio of a monolayer catalyst in case the wall thickness of the support is the same or smaller than the escape depth [32]. The thickness of the silica walls in case of our SBA-15 samples is estimated to be about $3 \mathrm{~nm}$ based on TEM, which is to be compared with the escape depth of a Silicon $2 p$ electron of $3.8 \mathrm{~nm}$ ( $\mathrm{Mg} \mathrm{K} \alpha$ radiation). In fact, a comparison of the V/Si XPS ratio of the highly dispersed (dehydrated) catalysts $(0.029,0.061)$ with the actual volume V/Si ratio of our catalyst as determined by ICP $(0.033$, 0.067 ) yields a surprisingly good agreement considering the fact that the XPS signals are evaluated on basis of empirical cross sections. The lower V/Si ratio of the hydrated $(0.024$, $0.052)$ compared to the dehydrated $(0.029,0.061)$ samples can be ascribed to the presence of hydrated $\mathrm{V}_{2} \mathrm{O}_{5}$ species (see discussion below). However, a contribution from diffusion of a small amount of vanadia, an inhomogeneous distribution of vanadia particle sizes within the sampled region or a modification of the vanadium XPS cross section due to the presence of water not be ruled out.
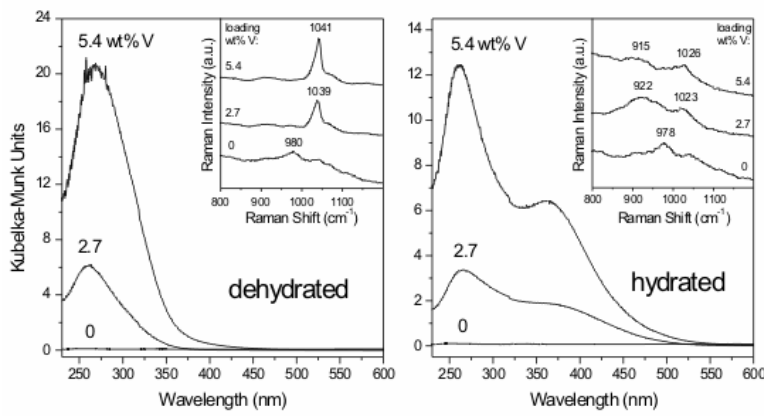

Figure 5: UV-VIS diffuse reflectance spectra of dehydrated (left) and hydrated (right) SBA-15 supported vanadia as well as blank SBA-15. The insets show the corresponding Raman spectra. The latter are offset for clarity.

UV-VIS spectra of the $2.7 \mathrm{wt} \%$ and $5.4 \mathrm{wt} \% \mathrm{~V} / \mathrm{SBA}-$ 15 catalyst as well as the blank SBA-15 support are depicted in Fig. 5 in their dehydrated (left panel) and hydrated (right panel) state. The corresponding Raman spectra are shown as insets. The dehydrated V/SBA-15 samples gives rise to an absorption band at $\sim 260 \mathrm{~nm}$. As shown previously, deconvolution gives rise to bands at 250 and $292 \mathrm{~nm}$, respectively [18]. The position of their maxima agrees well with that of orthovanadate reference compounds such as $\mathrm{Na}_{3} \mathrm{VO}_{4}$ and $\mathrm{Mg}_{3} \mathrm{~V}_{2} \mathrm{O}_{8}$. The corresponding Raman spectra are dominated by a band at $\sim 1040 \mathrm{~cm}^{-1}$ (see inset), which can be assigned to the $\mathrm{V}=\mathrm{O}$ bond of tetrahedrally coordinated vanadia [3-6,18]. However, the detailed assignment of this band is currently under debate [7,8]. In contrast to the V/SBA-15 samples, the blank SBA-15 support gives rise to only one Raman band at $\sim 980 \mathrm{~cm}^{-1}$, which is characteristic of the Si-OH stretching mode of surface hydroxyls [33]. Obviously, upon grafting of vanadia, its intensity decreases as a result of the reaction of $\mathrm{Si}-\mathrm{OH}$ with the vanadia precursor.

The hydrated V/SBA-15 samples shows an additional strong UV-VIS absorption band at $\sim 370 \mathrm{~nm}$, while the band at $\sim 260 \mathrm{~nm}$ is reduced in intensity compared to the dehydrated samples. This indicates that part of the tetrahedral species has been transformed into pseudo-octahedral $\mathrm{V}^{5+}$ ions by coordination to water molecules and subsequent polymerization. These structural changes are confirmed by the Raman spectra (see inset), which gives rise to bands characteristic of hydrated vanadia species and which strongly resemble those of xerogels $\mathrm{V}_{2} \mathrm{O}_{5} \cdot n \mathrm{H}_{2} \mathrm{O}$ [34].

The Raman results suggest that the hydrated state resembles a water-containing vanadia gel $\left(\mathrm{V}_{2} \mathrm{O}_{5} \cdot n \mathrm{H}_{2} \mathrm{O}\right)$. Upon dehydration, a dramatic change in molecular structure from pseudo-octahedrally to tetrahedrally coordinated monolayer-type vanadium oxide is observed as inferred from UV-VIS and Raman spectroscopy. The results of our XPS analysis complete this picture. Upon calcination in oxygen, the hydrated vanadia gel, which exhibits characteristics of $\mathrm{V}_{2} \mathrm{O}_{5}$-like polyvanadate species (BE: $517.4 \mathrm{eV}$ ) largely transforms into highly dispersed vanadium oxide (BE: $518.7 \mathrm{eV}$ ) with a significantly smaller ensemble size as evidenced by the increase in the intensity ratio of the $518.7 \mathrm{eV}$ and $517.4 \mathrm{eV}$ peak. In contrast to XPS, Raman appears to be insensitive to the presence of two $\mathrm{V}^{5+}$ states indicating that with the latter technique we see only part of the system. Thus, XPS yields important information on changes in catalyst dispersion, which is complementary to the information obtained from the above optical methods. Besides, XPS can provide information on surface composition and oxidation states emphasizing its great potential for catalyst characterization, especially in light of the recent progress in the development of XPS instrumentation demonstrating its use under in situ conditions at pressures in the mbar range [35].

\section{Conclusions}

We have demonstrated the use of XPS as a sensitive tool to study the dispersion of metal oxide catalysts for nanostructured SBA-15-supported vanadia model catalysts. XPS characterization of the dehydrated catalysts reveals an overall positive binding energy shift of the V2 $\mathrm{p}_{3 / 2}$ state compared to their hydrated state, which is the result of a substantial reduction in vanadium oxide cluster size during calcination. Thus, XPS can provide direct information on the dispersion as well as the oxidation states of metal oxide catalysts highlighting its importance for the characterization of metal oxide catalysts besides optical methods such as UV-VIS and Raman spectroscopy. 


\section{Acknowledgements}

The authors gratefully acknowledge Genka TzolovaMüller for performing the UV-VIS experiments, Gisela Lorentz for performing the BET measurements, Rita Her-

\section{References and Notes}

[1] G. Centi, F. Cavani and F. Trifiro, Selective oxidation by heterogeneous catalysis, Kluwer Academic/Plenum Publishers, NY 2000.

[2] B. Gryzbowska-Swierkosz, Top. Catal. 11/12 (2000) 23.

[3] M. Schraml-Marth, M., A. Wokaun, M. Pohl, H.L. Krauss, J. Chem. Soc. Faraday Trans. 87 (1991) 2635.

[4] S. Xie, E. Iglesia, E., A.T. Bell, Langmuir 16 (2000) 7162.

[5] X. Gao, S.R. Bare, B. Weckhuysen, I.E. Wachs, J. Phys. Chem. B 102 (1998) 10842.

[6] E.V. Kondratenko, M. Cherian, M. Baerns, D. Su, R. Schlögl, X. Wang, I.E. Wachs, J. Catal. 234 (2005) 131.

[7] N. Magg, B. Immaraporn, J.B. Giorgi, T. Schroeder, M. Bäumer, J. Döbler, Z. Wu, E. Kondratenko, M. Cherian, M. Baerns, P.C. Stair, J. Sauer, H.-J. Freund, J. Catal. 226 (2004) 88.

[8] D.E. Keller, D.C. Koningsberger, B. Weckhuysen, J. Phys. Chem. B 110 (2006) 14313.

[9] S.T. Oyama, G.T. Went, K.B. Lewis, A.T. Bell, G.A. Somorjai, J. Phys. Chem. 93 (1989) 6786.

[10] A.M. Venezia, Catal. Today 77 (2003) 359.

[11] K. Inumaru, M. Misono, T. Okuhara, Appl. Catal. A 149 (1997) 133.

[12] G.C. Bond, J.P.Zurita, S. Flamerz, Appl. Catal. 27 (1986) 353.

[13] N.K. Nag, F.E. Massoth, J. Catal. 124 (1990) 127.

[14] F.J. Gil-Llambias. A.M. Escudey, J.L.G. Fierro, A. Lopez Agudo, J. Catal. 95 (1985) 520.

[15] B. Horvath, J. Strutz, J. Geyer-Lippmann, E.G. Horvath, Z. Anorg. Allg. Chem. 483 (1981) 205.

[16] D.C.M. Dutoit, M. Schneider, P. Fabrizioli, A. Baiker, J. Mater. Chem. 7 (1997) 271.

[17] M. Wark, M. Koch, A. Brückner, W. Grünert, J. Chem. Soc. Faraday Trans. 94 (1998) 2033.

[18] C. Hess, J.D. Hoefelmeyer, T.D. Tilley, J. Phys. Chem. B 108 (2004) 9703. bert for preparation of some of the samples and Dr. Oksana Storcheva for performing the EPR experiments. The work is supported by SFB 546 of the Deutsche Forschungsgemeinschaft (DFG). C. H. thanks the DFG for providing an Emmy Noether fellowship.

[19] C. Hess, U. Wild, R. Schlögl, Microp. Mesop. Mater. 95 (2006) 339 and references therein.

[20] C. Hess, Surf. Sci. 600 (2006) 3695.

[21] C. Hess, M.H. Looi, S.B. Abd Hamid, R. Schlögl, Chem. Comm. (2006) 451.

[22] C. Hess, I.J. Drake, J.D. Hoefelmeyer, T.D. Tilley, A.T. Bell, Catal. Lett. 105 (2005) 1.

[23] P.C. Thüne, C.P.J. Verhagen, M.J.G. van der Boer, J.W. Niemantsverdriet, J. Phys. Chem. B 101 (1997) 8559 and references therein.

[24] R.M. van Hardevelt, P.L.J. Gunter, L.J. van Ijzendoorn, W. Wielraaijer, E.W. Kuipers, J.W. Niemantsverdriet, Appl. Surf. Sci. 84 (1995) 1367.

[25] T.L. Barr, Modern ESCA, CRC Press, Boca Raton, 1994.

[26] D. Briggs, M. P. Seah, Practical Surface Analysis, Wiley, Chichester, 1990.

[27] Referring to the $\mathrm{Si} 2 \mathrm{p}$ signal at $103.6 \mathrm{eV}\left(\mathrm{SiO}_{2}\right)$ charging correction is $<0.5 \mathrm{eV}$ for $\mathrm{V} / \mathrm{SiO}_{2} / \mathrm{Si}$.

[28] G.A. Sawatzky, D. Post, Phys. Rev. B 20 (1979) 1546.

[29] M.A. Eberhardt, A. Proctor, A. Houalla, D.M. Hercules, J. Catal. 160 (1996) 27 and references therein.

[30] G.K. Wertheim, Z. Physik. B 66 (1987) 53.

[31] T. Gross, M. Ramm, H. Sonntag, W. Unger, H.M. Weijers, E.H. Adem, Surf. Interface Anal. 18 (1992) 59.

[32] F.P.J.M. Kerkhof, J.A. Moulijn, J. Phys. Chem. B 83 (1979) 1612.

[33] R.H. Stolen, G.E. Walrafen, J. Chem. Phys. 64 (1976) 2623.

[34] L. Abello, E. Husson, Y. Repelin, G. Lucazeau, J. Solid State Chem. 56 (1985) 379.

[35] H. Bluhm, M. Hävecker, E. Kleimenov, A. Knop-Gericke, A. Liskowski, R. Schlögl, D.S. Su, Top. Catal. 23 (2003) 99. 